\title{
Studies of the Expression of the Wiskott-Aldrich Syndrome Protein
}

Donn M. Stewart, ${ }^{*}$ Stephanie Treiber-Held, ${ }^{\star}$ Carole C. Kurman, ${ }^{*}$ Fabio Facchetti, ${ }^{\ddagger}$ Luigi D. Notarangelo, ${ }^{\S}$ and David L. Nelson ${ }^{\star}$ ${ }^{*}$ National Institutes of Health, National Cancer Institute, Metabolism Branch, Bethesda, Maryland 20892; ${ }^{\ddagger}$ Departments of Pathology and $\S$ Pediatrics, University of Brescia, 25123 Brescia, Italy

\begin{abstract}
The Wiskott-Aldrich syndrome (WAS) is an X-linked disorder characterized by thrombocytopenia, eczema, disorders in cell-mediated and humoral immunity, and a proclivity to lymphoproliferative disease. The gene responsible encodes a 53-kD proline-rich protein of unknown function (WASP). We produced a FLAG-WASP fusion protein that was used to immunize mice and produce mAbs against WASP. Using monoclonal anti-WASP in Western immunoblots, we have determined that WASP is present in the cytoplasmic but not nuclear fraction of normal human peripheral blood mononuclear cells, in normal human platelets, in $\mathrm{T}$ lymphocytes, non-T lymphocytes, and monocytes. The protein is produced in the B cell immunoblastic cell line DS-1, in normal EBV-transformed B cell lines, and in HEL92.1.7, but is barely detectable in MOLT-4 and not detectable in K562. WASP was present in two of four EBV-transformed cell lines from WAS patients. Splenic tissue immunostaining was performed in two patients, and the results correlated with the results of the Western blots. Sequence analysis of WASP cDNA from two patients who produce WASP show mutations causing amino acid substitutions. These studies establish a foundation for further studies aimed at understanding the function of WASP. (J. Clin. Invest. 1996. 97: 2627-2634.) Key words: immunodeficiency, congenital • antibodies, monoclonal • immunoblotting • immunohistochemistry $\bullet$ mutation
\end{abstract}

\section{Introduction}

The Wiskott-Aldrich syndrome (WAS) ${ }^{1}$ is an X-linked recessive disorder characterized by thrombocytopenia, eczema, immunodeficiency in both humoral and cell-mediated responses, and a tendency toward immunoproliferative disease $(1,2)$. The gene responsible was recently cloned, and encodes a 502 amino acid proline-rich protein with a predicted molecular weight of $53 \mathrm{kD}$ that has been termed WASP (3-5). The protein shares no homology with any known protein, and its function is unknown. Studies of WASP expression revealed a $2.0-\mathrm{kb}$ mRNA present in fetal spleen and thymus, in the erythroleu-

Address correspondence to David L. Nelson, National Institutes of Health, National Cancer Institute, Metabolism Branch, Bldg. 10, Rm. 4N-115, 9000 Rockville Pike, Bethesda, MD 20892. Phone 301-4963024; FAX: 301-496-9956; E-mail: dln@helix.nih.gov

Received for publication 10 January 1996 and accepted in revised form 23 February 1996.

1. Abbreviations used in this paper: RT, reverse transcriptase; WAS, Wiskott-Aldrich syndrome; WASP, WAS protein.

The Journal of Clinical Investigation

Volume 97, Number 11, June 1996, 2627-2634 kemia cell line HEL, and in the megakaryocytic cell line MEG-01, but no message was detected in the T cell line Jurkat (3). The presence of a possible nuclear localization motif, proline-rich sequences, and an acidic $\mathrm{COOH}$ terminus suggests that WASP may be a transcription factor (3). An alternative hypothesis is that the proline-rich portions may be involved in signal transduction involving interaction with $\mathrm{SH} 3$ domains of other proteins (3). Additional studies have shown that the same gene is mutated in X-linked thrombocytopenia, which can be considered an attenuated form of the WAS (6-8).

To better define the tissue expression pattern, subcellular location, and, ultimately, the function of WASP, we have produced $\mathrm{mAbs}$ to this protein. We describe here results of a series of investigations using these antibodies in normal tissues and in patients with WAS.

\section{Methods}

Human subjects. Four patients with WAS were studied. Patients were evaluated and treated at the Department of Pediatrics, University of Brescia, Italy. Patient FS was 18 mo of age, patient MD was 3 $\mathrm{yr}$ of age, and patients MM and IA were $2.5 \mathrm{yr}$ of age. All had severe thrombocytopenia with platelet counts ranging from 2,000 to 32,000 with reduced mean platelet volume (range 3.8-4.3 fl, with normal being 7-11 fl). In addition, patient MM has persistent, severe eczema and recurrent infections. Patients MD and IA have manageable eczema, but no evidence for infections or autoimmunity. Patient FS had autoimmune hemolytic anemia that required prolonged treatment with high-dose prednisolone. The patient FS has been evaluated for WASP mutation previously (patient \#2 in Wengler et al. [9]), and has a frameshift mutation in exon I leading to an early stop codon. The molecular defects in the WASP gene of patients IA and MD are discussed in this paper, and the defect in patient MM has not been determined. Normal spleen tissue was obtained from five patients seen at the same institution, who underwent splenectomy after trauma, and who did not suffer immunodeficiency or thrombocytopenia. Normal PBMC were obtained from volunteer donors at the Clinical Center, National Institutes of Health, Bethesda, MD.

Production of WASP fusion proteins. Peripheral blood mononuclear cells from a normal volunteer were obtained by density-dependent centrifugation as previously described (10). Total RNA was prepared from these cells by guanidine thiocyanate lysis/phenol extraction using the RNA Isolation kit from Stratagene Inc. (La Jolla, CA). Polyadenylated RNA (mRNA) was isolated from total RNA by latex-oligo dT binding using the Oligotex kit from Qiagen Inc. (Chatsworth, CA). cDNA was prepared from the mRNA with reverse transcriptase (RT) using the cDNA Cycle kit from Invitrogen Corp. (San Diego, CA). Approximately $100 \mathrm{ng}$ of mRNA was used in a $20 \mu \mathrm{l}$ reaction. The following oligonucleotide primers were prepared matching sequences flanking the published WASP coding sequence (3-5) with restriction enzyme sites incorporated to allow directional inframe cloning into the expression vectors: primer 1, 5'-CGTAAAGCTTATGAGTGGGGGCCCAATGGGAGGA (HindIII, cDNA positions 35 to 57); primer 2, 5'-GCTAGGATCCATGAGTGGGGGCCCAATGGGAGGAAGG (BamHI, cDNA positions 35 to 61); primer 3, 5'-CATGTCTAGAGTCATCCCATTCATCATCTTCATCTTC (XbaI, cDNA positions 1540 to 1514). PCR was performed using the cDNA as template and the primer pairs $1+3$ and 2 
$+3.50 \mu \mathrm{l}$ reactions containing $2 \mu \mathrm{l}$ of the RT reaction, $1 \mu \mathrm{M}$ primers, $250 \mu \mathrm{M}$ deoxynucleoside triphosphates and $5 \mathrm{U}$ Taq polymerase (Perkin-Elmer Corp., Foster City, CA) were overlaid with $70 \mu \mathrm{lmin}-$ eral oil and cycled as follows: $94^{\circ} \mathrm{C}$ for $1 \mathrm{~min}, 60^{\circ} \mathrm{C}$ for $1 \mathrm{~min}, 72^{\circ} \mathrm{C}$ for $2 \mathrm{~min}, 35$ cycles, followed by $72^{\circ} \mathrm{C}$ for $7 \mathrm{~min}$, then held at $4^{\circ} \mathrm{C}$. Full length PCR product was consistently obtained. The PCR product was digested with either HindIII or BamHI, and then with EcoRI. Restriction endonucleases were obtained from Boehringer Mannheim Biochemicals, Indianapolis, IN. (The XbaI site in primer 3 was not used in producing the fusion proteins in these experiments; the EcoRI site at 1356 in the WASP cDNA sequence was used instead.) Digested PCR product was purified by electrophoresis in low melting point agarose. The prokaryotic expression vectors pFLAG-ATS (Eastman Kodak Co., Rochester, NY) or pGEX-2T (Pharmacia LKB Biotechnology, Inc., Piscataway, NJ) were digested with HindIII or BamHI, respectively, and EcoRI, and treated with calf intestine alkaline phosphatase (Life Technologies, Gaithersburg MD). Digested and purified PCR product was ligated into the expression vectors using T4 DNA ligase (Life Technologies). Competent cells (DH5 $\alpha$; Gibco BRL, Grand Island, NY) were transformed, and ampicillinresistant colonies tested for the presence of insert by alkaline lysis plasmid miniprep and restriction enzyme digestion. FLAG-WASP plasmids were sequenced across the vector-insert junction at the $5^{\prime}$ end to confirm in-frame ligation and to verify the identity of the insert as WASP cDNA. Sequencing was done using the Sequenase kit (Amersham Corp., Arlington Heights, IL) and the N-26 primer supplied with the expression vector. Expression of FLAG-WASP or GST-WASP fusion proteins was done by diluting overnight cultures in LB with $50 \mu \mathrm{g} / \mathrm{ml}$ ampicillin (1:100) in the same medium, growing for $2 \mathrm{~h}$ at $37^{\circ} \mathrm{C}$, and then adding IPTG to $500 \mu \mathrm{M}$. Cultures were grown for another $2 \mathrm{~h}$ at $37^{\circ} \mathrm{C}$, and the cells were collected by centrifugation. Cells were lysed by resuspending in 1/10 culture vol of 50 $\mathrm{mM}$ Tris- $\mathrm{HCl}, \mathrm{pH} 8.0,5 \mathrm{mM}$ EDTA, $50 \mu \mathrm{g} / \mathrm{ml}$ sodium azide, $250 \mu \mathrm{g} /$ $\mathrm{ml}$ lysozyme. After $5 \mathrm{~min} 1 / 100$ culture vol $1.5 \mathrm{M} \mathrm{NaCl}, 0.1 \mathrm{M} \mathrm{MgCl}_{2}$, $20 \mu \mathrm{g} / \mathrm{ml}$ DNAseI, $50 \mu \mathrm{g} / \mathrm{ml}$ ovomucoid protease inhibitor (Sigma Chemical Co., St. Louis, MO) was added. The lysate was centrifuged at $18,000 \mathrm{~g}$ for $30 \mathrm{~min}$ at $4^{\circ} \mathrm{C}$. The pellet of insoluble material containing the fusion proteins was solubilized in $1 / 50$ culture vol $0.1 \mathrm{M}$ glycine $/ \mathrm{NaOH}, \mathrm{pH}$ 9.0, $8 \mathrm{M}$ urea after the method of Frorath et al. (11). This solution was centrifuged at $15,000 \mathrm{~g}$ for $15 \mathrm{~min}$ and the supernatant passed over a Sephadex G25 column (Pharmacia) equilibrated with $0.1 \mathrm{M}$ glycine/NaOH, pH 9.0, to remove the urea. Column void volumes were collected, and the solution containing GST-WASP was saved at this point. In the case of FLAG-WASP, the protein solution

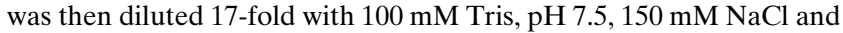
passed over an anti-FLAG affinity column. The bound FLAG-WASP fusion protein was eluted in fractions with $0.1 \mathrm{M}$ glycine/ $\mathrm{HCl}, \mathrm{pH} 3.0$, and added to $1 / 20$ elution fraction, vol $1 \mathrm{M}$ Tris- $\mathrm{HCl}, \mathrm{pH}$ 8.0. Protein concentration in the fractions was determined by the method of Bradford (12). A total of 3-4 mg of affinity-purified FLAG-WASP could be obtained from a 500-ml culture using this method.

Immunization and hybridoma cell line production. Immune rabbit serum was produced by immunization of NZY rabbits as described (10) using FLAG-WASP. For mAb production, BALB/c mice were immunized by intraperitoneal injection of $5 \mu \mathrm{g}$ of affinity-purified FLAG-WASP fusion protein in $300 \mu \mathrm{l}$ of PBS ( $80 \mathrm{mM} \mathrm{Na}_{2} \mathrm{HPO}_{4}$, $20 \mathrm{mM} \mathrm{NaH}_{2} \mathrm{PO}_{4}, 100 \mathrm{mM} \mathrm{NaCl}, \mathrm{pH}$ 7.4) at weekly intervals for $5 \mathrm{wk}$. $3 \mathrm{~d}$ before fusion an intravenous injection of the same was given. Spleens from two immunized mice were harvested and polyethylene glycol fusion with the myeloma line NS-1 (American Type Culture Collection, Rockville, MD) was performed essentially as described by Fuller et al. (13) except no feeder layer was used. Fused cells were plated in 720 wells on 96-well plates. Supernatants from the 96-well plates were screened for anti-WASP activity as described below.

Screening of hybridoma supernatants. An ELISA was developed to measure anti-WASP antibodies as follows. Affinity-purified FLAG-WASP or GST-WASP lysate was diluted in carbonate-bicarbonate buffer, $\mathrm{pH} 9.6,(10)$, and $150 \mu \mathrm{l}$ of various dilutions were used to coat polycarbonate microtiter plates overnight at $4^{\circ} \mathrm{C}$. The plates were washed, and $100 \mu \mathrm{l}$ preimmune and 6-wk immune rabbit sera diluted 1:1,000 in PBS- $0.05 \%$ Tween- 20 containing $1 \%$ FCS was added to the coated wells and incubated overnight at $4^{\circ} \mathrm{C}$. The plates were washed, and $100 \mu \mathrm{l}$ of a 1:400 dilution of alkaline phosphatase-conjugated goat anti-rabbit IgG (Boehringer Mannheim Biochemicals, Indianapolis, IN) added and incubated at room temperature for $2 \mathrm{~h}$. The plates were again washed and $100 \mu \mathrm{l}$ of substrate (Sigma 104 phosphate substrate tablet; Sigma Chemical Co.) at $1 \mathrm{mg} / \mathrm{ml}$ in diethanolamine buffer, $\mathrm{pH} 9.8,(10)$ was added and incubated for $30 \mathrm{~min}$ at room temperature. The plates were read in a spectrophotometer and that dilution of FLAG-WASP $(2 \mu \mathrm{g} / \mathrm{ml})$ or GST-WASP lysate (1:400) which gave an $\mathrm{OD}_{405}=1$ was chosen for plate coating.

To screen hybridoma supernatants, FLAG-WASP-coated plates were washed, and 50 or $100 \mu$ l of hybridoma supernatant was added per well. Four wells containing culture medium alone served as the negative control, and two wells containing a 1:3,200 dilution of mouse serum from FLAG-WASP immunized mice obtained at the time of splenic harvesting were used as the positive control on each plate. Supernatants and controls were incubated for $2 \mathrm{~h}$ at room temperature, the plates were washed, $100 \mu \mathrm{l}$ of alkaline phosphatase-conjugated goat anti-mouse IgG and IgM (Boehringer Mannheim Biochemicals) diluted 1:5,000 was added to each well, and the plates were incubated for $2 \mathrm{~h}$ at room temperature. After washing, the wells received $100 \mu \mathrm{l}$ of diethanolamine buffer containing substrate, and the reaction was allowed to proceed for $1 \mathrm{~h}$. The plates were read in a spectrophotometer and those wells scoring $>3 \mathrm{SD}$ above the negative control were considered positive. For the initial screening ( $6 \mathrm{~d}$ after fusion) and for the second screening (13 d after fusion) all 720 cultures were screened. Those cultures testing positive were screened by ELISA for reactivity to an unrelated FLAG fusion protein (FLAG-BTK [14]) to eliminate lines producing anti-FLAG antibodies. Eight lines tested positive against FLAG-WASP and negative against FLAG-BTK. These lines were placed in 24-well plates. When growth covered $\sim 50 \%$ of the well surface, the lines were subsequently expanded in flasks. They were tested for ability to recognize denatured FLAGWASP on Western spot tests and were all positive. These lines were cloned in microtiter plates beginning at 1,000 cells/well and extending to 0.49 cells/well. Those positive wells which by Poisson analysis were clonal were rescreened by ELISA against both FLAG-WASP and GST-WASP, expanded, and injected into Pristane-primed mice to generate ascites. One line produced IgG $2 \mathrm{~b}$ kappa, one produced $\mathrm{IgG}$ 1 lambda, and the rest produced IgG 1 kappa. The clones used in this paper, 3F3-B5, 3F3-A5, and 11G8-B7 all produced identical patterns on Western immunoblots of WASP and non-WASP recombinant proteins and cell lysates from normal and WASP patients.

Isolation of blood leukocyte cell subpopulations. PBMC were isolated from healthy donors as described above. A cell subpopulation enriched for $\mathrm{T}$ lymphocytes $(\mathrm{E}+)$ was prepared by sheep erythrocyte rosette as previously described (10). Platelets were isolated from a normal volunteer by isosmotic density centrifugation using arabino-galactan solutions (15) in one experiment, and by centrifugation of the first wash supernatant from a PBMC preparation at 2,000 $\mathrm{g}$ for $10 \mathrm{~min}$ in another experiment. Monocytes were prepared from a lymphopheresis of a healthy donor by elutriation. For FACS analysis, cells from each fraction were washed twice in PBS, $0.1 \% \mathrm{NaN}_{3}, 1 \% \mathrm{BSA}$, and incubated at $4^{\circ} \mathrm{C}$ for 10 min with human immunoglobulin for blocking. One million cells were stained for $30 \mathrm{~min}$ in the dark with saturating concentrations of phycoerythrin-labeled antibodies, then washed and fixed with $1 \%$ paraformaldehyde. Analyses were performed on a FACSort (Becton-Dickinson \& Co., San Jose, CA).

Cell lines. The following human cell lines were obtained from ATCC: MOLT-4 (T cell), HEL 92.1.7 (erythroleukemia), K-562 (chronic myelogenous leukemia), MRC-5 (fibroblast), and LL 29 (fibroblast). The cell line DS-1 (B cell immunoblast) has been described elsewhere (16).

Production of EBV-transformed cell lines from WAS patients. EBV-transformed cell lines were obtained from the WAS patients 
and from a normal individual by incubating PBMC with the B95-8 strain of EBV as described (17).

Immunostaining. Splenic specimens were obtained at time of splenectomy for thrombocytopenia from the WAS patients IA and FS. Normal spleen tissue was obtained from five patients with traumatic rupture. Fresh tissue blocks were immediately frozen in liquid nitrogen precooled isopentane and stored at $-80^{\circ} \mathrm{C}$ until used. $5-\mu \mathrm{m}$ sections were air dried for $18 \mathrm{~h}$, fixed in acetone for $10 \mathrm{~min}$, and then stained following the streptavidin-biotin complex immunoperoxidase technique (DAKO Corp., Carpenteria, CA). Anti-WASP monoclonal ascites 11G8-B7 was applied at a dilution of 1:50. Negative controls omitting the anti-WASP or substituting an irrelevant antibody were performed on other sections taken from the same specimens. Immunostaining to recognize platelets was performed using the $\mathrm{mAb}$ to CD61 (DAKO) at a dilution of 1:100.

Western immunoblot analysis of WASP expression. FLAG-WASP and GST-WASP fusion proteins were diluted directly into SDS sample buffer (126 mM Tris-HCl, pH 6.8, 20\% glycerol, 4\% SDS, $2 \%$ 2-mercaptoethanol, $0.005 \%$ bromophenol blue). Platelet pellets were dissolved in SDS sample buffer at $2 \times 10^{10} / \mathrm{ml}$. PBMC were isolated as described above. For cytoplasmic lysates, cells were lysed in $1 \%$ NP-40, 50 mM Tris- $\mathrm{HCl}$, pH 7.5, $100 \mathrm{mM} \mathrm{NaCl,} 2$ mM PMSF. PBMC and subpopulations were lysed at $4 \times 10^{8}$ cells $/ \mathrm{ml}$, and cell lines were lysed at $1 \times 10^{8} \mathrm{cells} / \mathrm{ml}$. The lysates were centrifuged at 2,000 $\mathrm{g}$ and the supernatant diluted in an equal volume of SDS sample buffer. The pellets containing the nuclei were washed twice with NP-40 lysis buffer and dissolved in the same volume of SDS lysis buffer that had been added to the supernatant. For whole cell lysates, cells were suspended in a volume of PBS in the same proportions as NP-40 lysis buffer, and the suspension lysed in an equal volume of SDS sample buffer. $10 \mu \mathrm{l}$ of the platelet and nuclear lysates, and $20 \mu \mathrm{l}$ of the cell lysates were applied to each lane for polyacrylamide gel electrophoresis.

SDS-polyacrylamide gel electrophoresis and transfer to PVDF (Millipore Corp., Bedford, MA) or nitrocellulose (Amersham Corp.) membranes were performed using equipment, gels, and buffers from Novex (San Diego, CA). Immunoblotting was performed as described (18) using anti-WASP hybridoma cell line supernatant or ascites as the primary antibody. Chemiluminescent detection was performed using goat anti-mouse IgG + IgM alkaline phosphatase conjugate or goat anti-mouse IgG horseradish peroxidase conjugate (Gibco BRL). Lumiphos-530 (Boehringer Mannheim) was used as the substrate for alkaline phosphatase detection, and Supersignal (Pierce Chemical Co., Rockford, IL) for horseradish peroxidase detection. To confirm protein transfer and visualize molecular weight markers, PVDF blots were stained with Coomassie blue, and nitrocellulose blots were stained with colloidal gold (Bio-Rad Laboratories, Hercules, CA).

Northern analysis of WASP mRNA expression. Polyadenylated RNA was obtained from $\mathrm{PBMC}$ as in the production of the fusion proteins described above. Polyadenylated RNA was prepared from cultured cell lines using the Fast-Track kit from Invitrogen Corp. These samples were subjected to formaldehyde-agarose gel electrophoresis and Northern blotting as described by Selden (19). The WASP cDNA insert used in the fusion protein production described above was purified by electrophoresis in low melting point agarose, labeled with $\alpha^{32} \mathrm{P}-\mathrm{dCTP}$ by random primer extension, and used as a hybridization probe. A human GAPDH cDNA was obtained from ATCC and was purified and labeled in the same way.

cDNA sequencing. cDNA was prepared from the WAS patient EBV cell lines as described above for producing the recombinant WASPs. PCR was performed as described above using the following primers: 5'-AGCCTCGCCAGAGAAGACAAGGGCAGAAAG (cDNA positions 1 to 30); 5'-GCCATGTCCTGCGGGGAGGAG CACAGGGCA (cDNA positions 1561 to 1590). This produced a PCR product of 1590-bp containing the entire coding sequence of WASP. Simultaneous negative controls in which the RNA was omitted from the RT reaction and the cDNA was omitted from the PCR produced no detectable product. These PCR products were cloned by ligating into the pCRII vector using the TA Cloning kit (Invitrogen
Corp.). A clone containing the full length PCR product was selected in each case, purified, and sequenced. Both manual sequencing using the Sequenase 2.0 kit (Amersham Corp.) and automated sequencing using the ABI 377 sequencer (Perkin-Elmer, Foster City, CA) were performed. Sequencing primers 20 bases in length were synthesized according to the reference cDNA sequence from both strands at $\sim 300$-bp intervals. Sequence data was compiled manually or with the AutoAssembler software from Perkin Elmer. Areas of abnormality were confirmed by repeating PCR, cloning, and sequencing.

\section{Results}

WASP expression in normal blood cells and selected cell lines. Fig. 1 shows the result of a protein immunoblot using supernatant from a cloned anti-WASP hybridoma line. The antibody detects only fusion proteins containing a WASP sequence. The fusion proteins containing WASP sequence are seen in several bands, representing the full size product and smaller partial degradation products, as frequently seen in prokaryotic expression systems $(20,21)$. Both GST and FLAG fusion proteins containing the unrelated Bruton's tyrosine kinase sequence (14) are not detected, and GST without a fusion partner is not detected. We conclude that the antibody contained in this hybridoma supernatant is able to recognize the denatured WASP protein sequence and is not reacting with the FLAG fusion partner of the immunogen. Monoclonal antiBruton's tyrosine kinase (14) or anti-FLAG similarly recognize specifically the protein sequences targeted by those antibodies on other protein blots containing the same recombinant proteins (data not shown).

Fig. 2 shows the result of a Northern blot used to detect WASP mRNA sequence in poly-A+ RNA from several different cell populations. WASP mRNA is abundant in PBMC

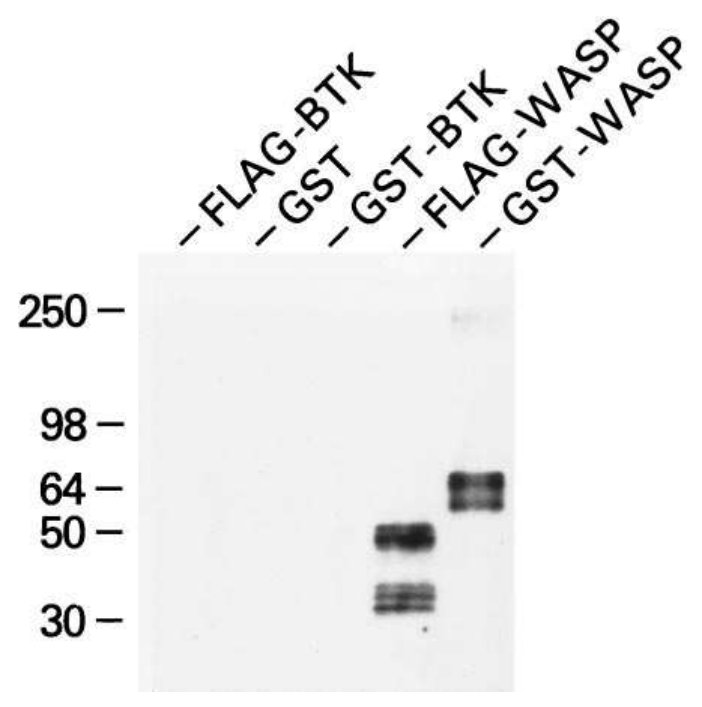

Figure 1. Western immunoblot of fusion proteins. $10 \mu \mathrm{l}$ of FLAGBTK or FLAG-WASP at $5 \mu \mathrm{g} / \mathrm{ml}$ in SDS sample buffer, or $10 \mu \mathrm{l}$ of GST, GST-BTK, or GST-WASP lysates diluted 1:100 in SDS sample buffer were subjected to gel electrophoresis and blotting as described in Methods. Supernatant from anti-WASP hybridoma clone 3F3-B5 diluted 1:1 with TTBS was used as the primary antibody. PVDF membranes and the alkaline phosphatase method were used. $M_{\mathrm{r}} \times$ $10^{-3}$ is shown in the left margin. 


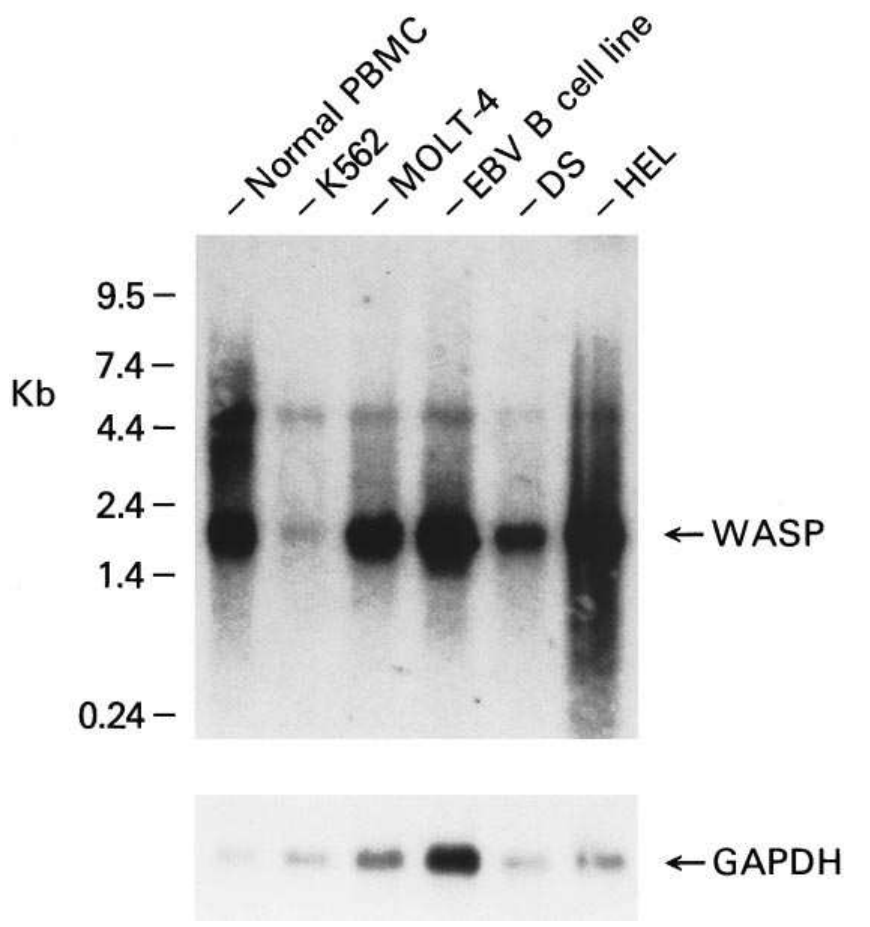

Figure 2. Northern blot hybridization of poly-A+ RNA from PBMC and various cell lines. $0.3-1.5 \mu \mathrm{g}$ of RNA was electrophoresed and subjected to blotting as described in Methods. The WASP cDNA used for the hybridization probe encompassed bases 35 to 1360. RNA standards in kilobases are shown. The blot was rehybridized with a GAPDH probe to assess RNA loading differences.

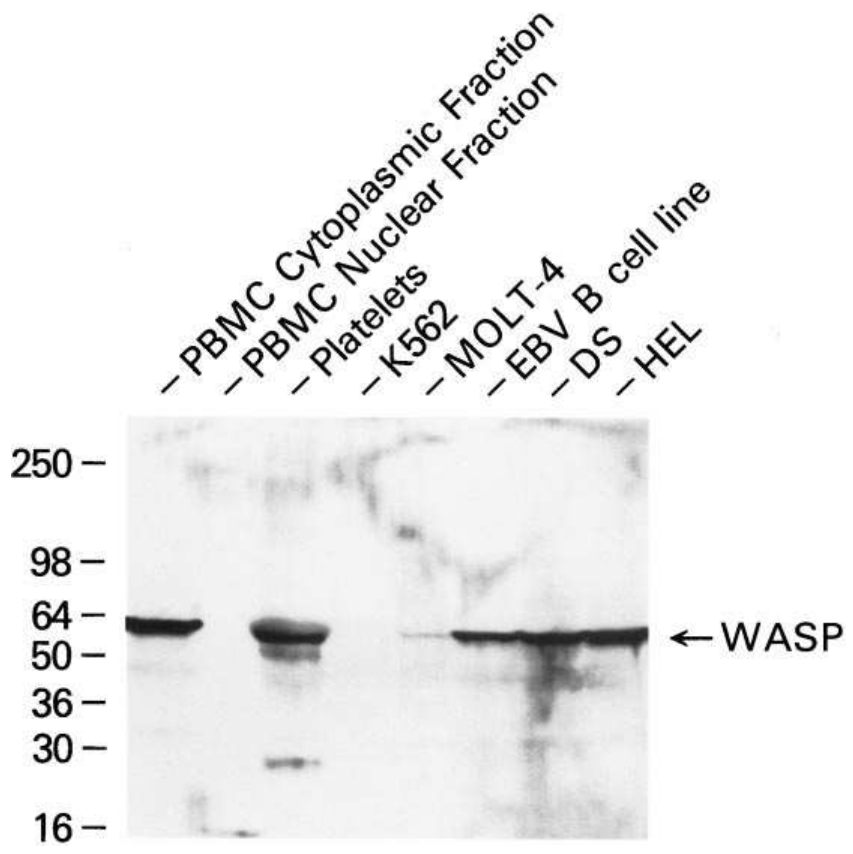

Figure 3. Anti-WASP Western immunoblot of proteins from PBMC and human cell lines. Sample preparation, electrophoresis, and immunoblotting were performed as described in Methods. Ascites from hybridoma clone 3F3-A5 diluted 1:10,000 was used as the primary antibody. A PVDF membrane and the alkaline phosphatase method were used. $M_{\mathrm{r}} \times 10^{-3}$ is shown in the left margin.
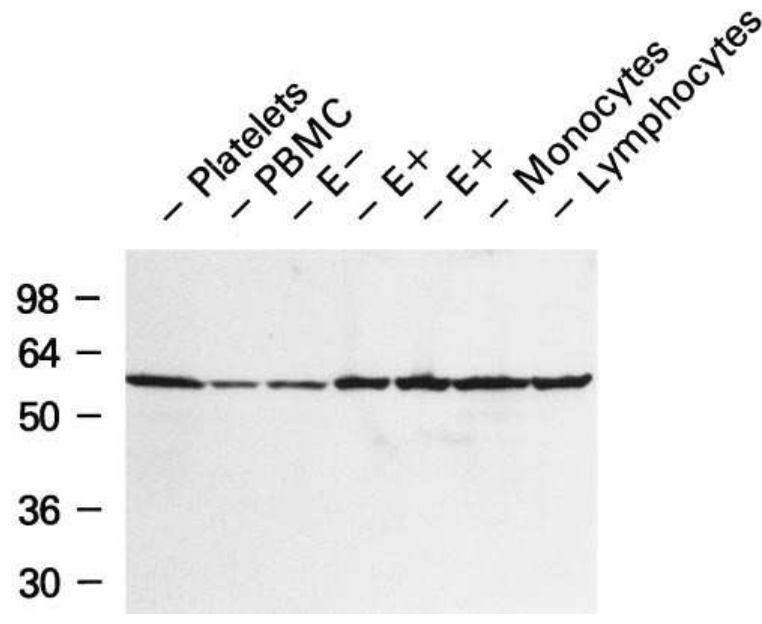

Figure 4. Anti-WASP Western immunoblot of various blood leukocyte fractions. Cell separation, sample preparation, electrophoresis, and immunoblotting were performed as described in Methods. In this experiment the platelets were isolated from the first wash supernatant of the PBMC isolation. E+ cells represent a population enriched for $\mathrm{T}$ lymphocytes by sheep erythrocyte rosette formation. E- cells are the remaining depleted cells. The PBMC, platelets, E+, and $\mathrm{E}-$ cells were from one normal donor. Monocytes obtained by elutriation and the monocyte-depleted lymphocytes are from another normal donor. Hybridoma clone 3F3-A5 ascites diluted 1:10,000 was used as the primary antibody. A PVDF membrane and the alkaline phosphatase method were used. $M_{\mathrm{r}} \times 10^{-3}$ is shown in the left margin.

and the cell lines MOLT-4, HEL 92.1.7, DS-1, and an EBVtransformed B-cell line from a normal volunteer. The indicated band has a size by our standards of $1.9 \mathrm{~kb}$. The faint band seen at $\sim 4.6 \mathrm{~kb}$ may be nonspecific binding to residual ribosomal RNA based on the results of similar Northern blots in which total RNA or the poly-A- fraction obtained after oligo dT selection was hybridized with the same WASP cDNA. The 1.9-kb band is depleted in the A-fraction, but the 4.6-kb band is greatly increased (data not shown).

Fig. 3 shows the detection of naturally occurring WASP in various cell types using monoclonal anti-WASP on a Western immunoblot. The band identified as WASP in the figure has an estimated mol wt of 59,000 D by our standards, and thus appears larger than the size predicted from its cDNA sequence. WASP is present in PBMC in the cytoplasmic fraction, but not in the nuclear fraction. It is also present in platelets. WASP was not detectable in the chronic myelogenous leukemia line K-562 and was barely detectable in the T cell line MOLT-4. The protein was detectable in an EBV-transformed B cell line, in the B cell immunoblastic cell line DS, and in the erythroleukemia cell line HEL 92.1.7 in similar amounts on a per cell basis. WASP was not detected in lysates of the human fibroblast cell lines MRC-5 and LL 29 (data not shown).

To identify the PBMC subpopulations containing WASP, we separated the cells into various types as discussed in Methods. The purity of the populations was assessed by $\mathrm{FACS}^{\circledR}$ analysis. The E+ cells were $88.8 \% \mathrm{CD} 3$ positive and the $\mathrm{E}$ - cells were $1.2 \%$ CD3 positive. Monocytes obtained by elutriation were $83.9 \%$ CD14 positive, and the corresponding monocytedepleted lymphocytes were $1.4 \%$ CD14 positive. For CD3 the monocytes were $1.5 \%$ positive and the lymphocytes $67.3 \%$ positive, and for CD16/56 the monocytes were $9.5 \%$ positive 


\author{
155 \\ $\downarrow$ \\ normal: GAG ATG CTT GGA CGA AAA TGC TTG ACG \\ glu met leu gly arg lys cys leu thr \\ pt MD: $\quad$ GAG ATG CTT GGA GGA AAA TGC TTG ACG \\ glu met leu gly gly lys cys leu thr
}

Figure 5. WASP cDNA abnormalities found in WAS patients known to produce normal amounts of protein. RT-PCR products containing the entire WASP coding sequence were cloned and sequenced on both strands. Sequences were normal except for the abnormalities shown. Abnormalities were confirmed by repeat PCR, cloning, and sequencing. and the lymphocytes $26.3 \%$ positive. Fig. 4 shows the results of a Western blot analysis of cytoplasmic proteins taken from the PBMC subpopulations, along with a platelet lysate. As can be seen, all nucleated PBMC cell types examined contained similar amounts of WASP on a per cell basis.

WASP cDNA sequence from WAS patients. WASP cDNA sequences from patients $\mathrm{MD}$ and IA were obtained by sequencing cloned RT-PCR products from EBV-transformed cell lines as described in Methods. The sequences are identical to the reference sequence as first reported by Derry et al. $(3,4)$ and corrected by Kwan et al. (5) except for the changes shown in Fig. 5. In patient MD, a $\mathrm{C}$ to $\mathrm{G}$ mutation at nucleotide posi-

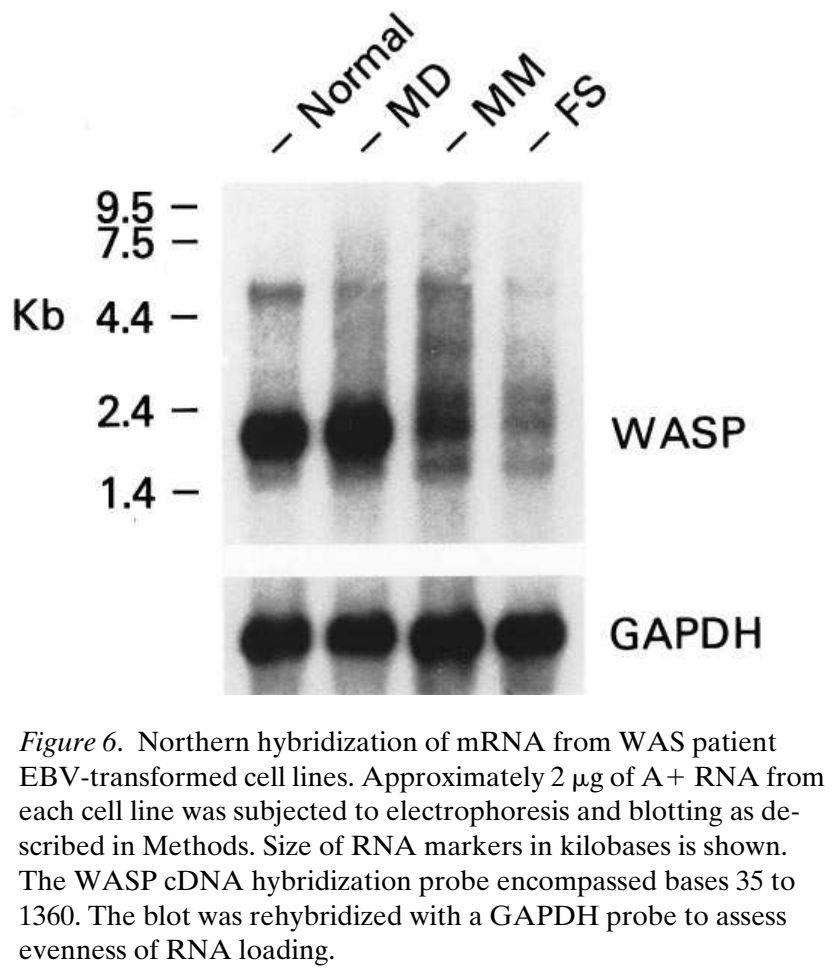

tion 155 would cause an arginine to glycine substitution at codon 41. In patient IA a C insertion after nucleotide 1016 produces a reading frameshift resulting in amino acid substitutions at codons 328, 329, 331, and 332. A G deletion just after nucleotide 1029 returns the reading frame to normal. FS is known by SSCP and subsequent sequence analysis to have a $116 \mathrm{C}$ deletion that results in a frameshift with a premature stop at codon 44 (9). The genetic defect in MM is not known.

WASP expression in WAS patients. Northern hybridization of poly-A + RNA from a normal and three of the WAS EBV cell lines with ${ }^{32} \mathrm{P}$-labeled WASP cDNA hybridization probe is shown in Fig. 6. The amount of WASP mRNA is greatly reduced in patients MM and FS. Patient MD, however, has a normal amount of normal sized mRNA. A Western immunoblot of cytoplasmic protein from the same cell lines is shown in Fig. 7. Patient MD has a normal amount of WASP,

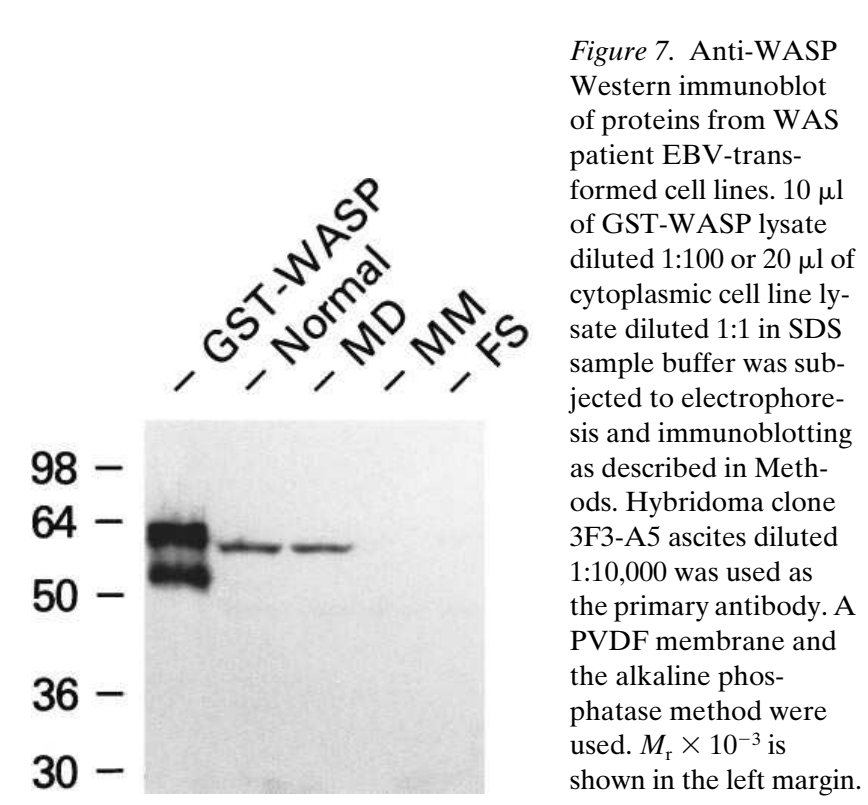



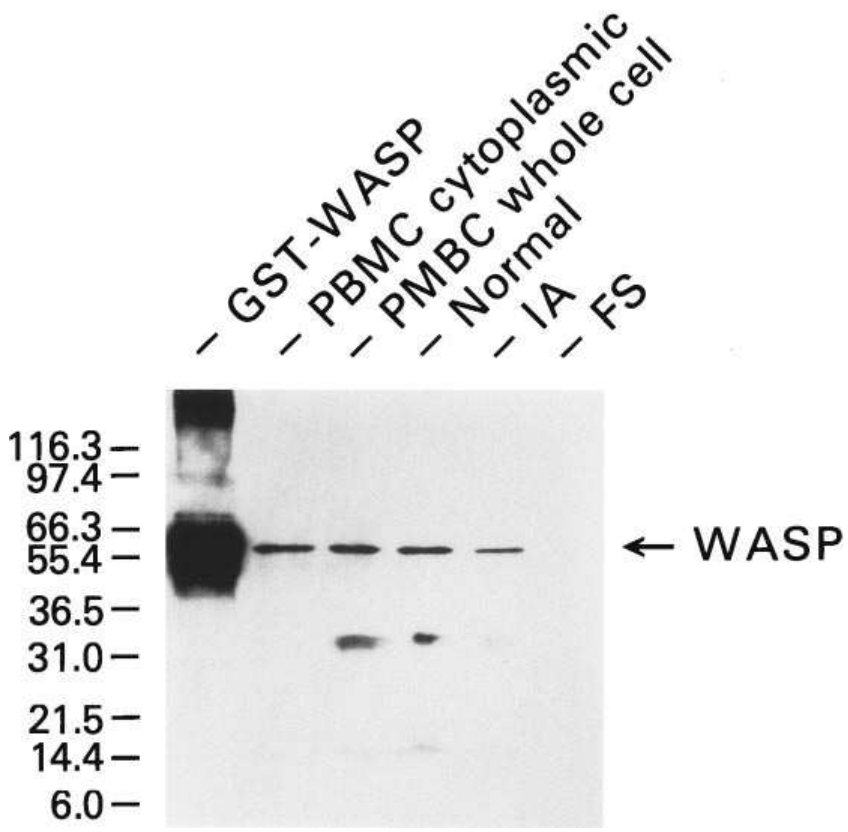

Figure 8. Anti-WASP Western immunoblot comparing proteins from EBV cell lines of the same two patients whose spleens were immunostained as shown in Fig. 9. Immunoblotting was performed as described in Methods. $10 \mu \mathrm{l}$ of a 1:10 dilution of GST-WASP lysate is in the first lane, and a cytoplasmic lysate of normal PBMC is in the next lane. Whole cell lysates of normal PBMC and EBV-transformed cell lines are in the remaining lanes. Anti-WASP ascites 3F3-A5 diluted 1:5,000 was used as the primary antibody, and nitrocellulose membranes and the peroxidase-based system were used. $M_{\mathrm{r}} \times 10^{-3}$ is shown in the left margin.

while the patients MM and FS have none detectable. Fig. 8 shows a similar immunoblot including proteins from an EBVtransformed cell line from IA. The immunoblot shows that patient IA has a normal-sized protein in a normal amount.

Anti-WASP immunostaining. Splenic tissue was prepared and stained for WASP as described in Methods using an immunoperoxidase technique. Fig. $9 A$ shows results typical of the normal controls. White pulp stains negatively, and the red pulp shows positivity mainly in stromal cells, including macrophages and epithelioid cells. Sinusoidal lining cells are only occasionally positive. The stain is exclusively cytoplasmic, agreeing with the results of the Western immunoblot (see above). The staining is diffuse or dot-like, with a paranuclear distribution. The dot-like pattern of reactivity is identical to the one shown when anti-CD61 is applied, recognizing platelets (not shown). However, in all cases tested, the number of CD61+ platelets is much higher than the number of paranuclear dots appearing with the anti-WASP staining.

Splenic tissue from two WAS patients is shown in Fig. 9, $B$ and $C$. Patient IA (Fig. $9 B$ ) has a normal WASP staining pattern, and patient FS (Fig. $9 C$ ) has no staining.

\section{Discussion}

The function of the Wiskott-Aldrich syndrome protein is not known at present. Since it is not homologous to any known proteins, only tentative hypotheses can be made based on its
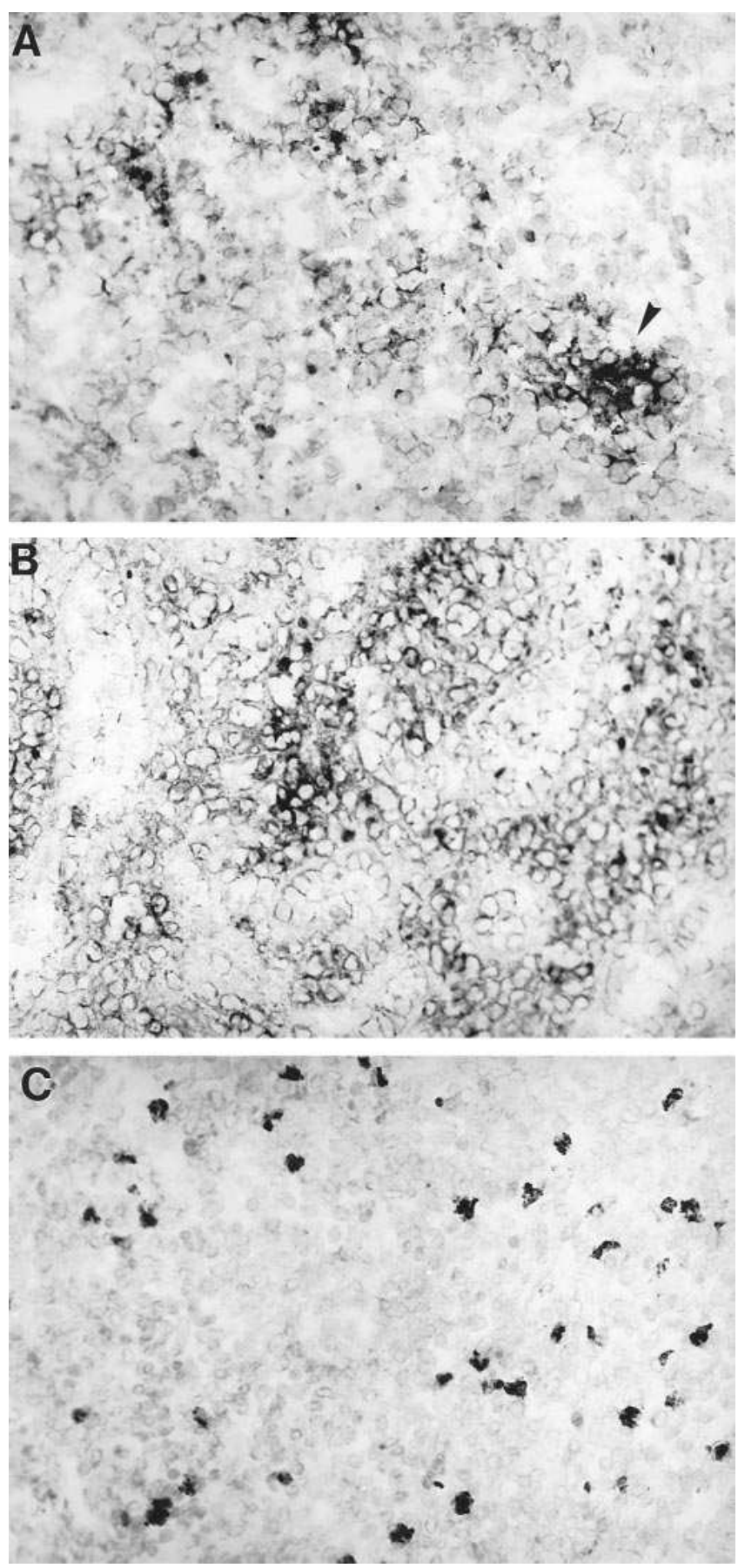

Figure 9. Anti-WASP immunoperoxidase staining of splenic red pulp. Ascites from hybridoma clone 11G8-B7 was used as described in Methods. Normal control $(A)$ and WAS patient IA $(B)$ show staining in the cytoplasm of stromal cells, as well as epitheliod cells (arrowhead). In contrast, no reactivity is recognizable in WAS patient FS $(C)$. The cells that stain intensely are eosinophils which contain high levels of endogenous peroxidase activity.

predicted sequence. Studies on the expression of this gene have been carried out at the RNA transcription level (3), but little is known about the protein itself. To study the function of WASP, we have developed mAbs that can be used for Western immunoblotting and immunostaining. Using these tech- 
niques, we have studied the expression of the WAS gene at the protein level in selected cell lines, and in peripheral blood cells, spleen, and EBV-transformed cell lines from normal individuals. We also studied WASP expression in spleen and EBV cell lines from WAS patients.

We have found that the protein is expressed in normal $\mathrm{PBMC}$ and is specifically present in the cytoplasmic fraction. It is also seen in the cytoplasm of splenic cells on tissue staining. Its absence from the nucleus suggests that it may not be a transcription factor, one of the possibilities that its discoverers considered (3). The possibility is certainly not ruled out, since many transcription factors are cytoplasmic proteins until appropriate cell activation occurs. Our observation of WASP in platelets, however, points to a possible role in cell structure or function that does not involve regulation of gene transcription. Studies of the cause of the platelet defect in WAS have shown a decrease in autologous platelet survival $(22,23)$ and impaired thrombogenesis (24). Normal matched donor platelets have normal survival in WAS patients $(22,23)$. The presence of WASP in platelets is consistent with the intrinsic platelet defect suggested by these studies. The protein is equally present in the cytoplasm of T cells, non-T lymphocytes, and monocytes, which is consistent with the characteristics of the immune deficiency syndrome, in which defects in cell-mediated and humoral immunity are seen (25-27). The distribution of WASP also correlates with the cell types in which abnormalities of structure and function have been seen (24, 28-36). In contrast to similar expression of WASP in T cells, non-T cells, and monocytes from peripheral blood, only monocyte-derived cells were shown to be positive on tissue sections. This may reflect lower sensitivity of immunostaining than Western blotting for protein detection. It is also possible that the protein is metabolized differently by the time the cells reach the peripheral circulation. Similarly, an interesting observation was the low protein level in the T cell line MOLT-4, despite abundant mRNA. This contrasts with the relatively high protein level in circulating $\mathrm{T}$ cells. This points out the importance of studying gene expression at the protein level as well as at the mRNA level. It is possible that post-transcriptional control of protein synthesis is being exerted, or that the protein has a shortened half-life in this cell line. It may be that WASP levels are reduced in freshly isolated, activated T cells, and studies are under way to investigate this hypothesis. T lymphocytes from WAS patients have been characterized as being in a state of abnormal activation (32).

Rivero-Lezcano et al. have shown that WASP associates with Nck, a cytoplasmic protein which contains two $\mathrm{SH} 2$ and three SH3 domains (37). The association was specific to one of the SH3 domains in Nck. These findings suggest that WASP acts in cell signaling pathways in the cytoplasm. Rivero-Lezcano et al. found the relative abundance of WASP to be $<3 \%$ in the nuclear fraction of HL60 cells, but they believe that a small fraction of the protein is present in the nucleus. These authors also noted that in SDS-PAGE the apparent molecular weight is larger than predicted, which we have also observed, and suggested that this might be due to its unusual amino acid content (37). Anomalously slow migration of proline-rich proteins in SDS-polyacrylamide gels under reducing conditions has been observed by others (38-41).

With regard to WASP expression in WAS patients, of the four EBV-transformed cell lines from WAS patients we studied, two lines produced no protein and little detectable mRNA, but the other two lines were normal in both respects.
One of the patients (FS) with both absent WASP mRNA and protein is known to have a frameshift mutation in exon 1 predicted to cause an early termination at codon 44 (9). The absence of mRNA in WASP nonsense mutations has been seen in other patients $(6,7)$. The same phenomenon has been observed with v-src frameshift mutations (42). The mechanism for this phenomenon has not been established but may result from rapid degradation of normally spliced but untranslatable message, or a type of RNA transcript scanning by the splicing apparatus that eliminates frameshifted transcripts. A brief discussion of the latter hypothesis can be found in Derry et al. (7). It should be noted that patient 4 reported in Kolluri et al. (6) has an exon 1 deletion predicted to cause the same early stop codon at 44 as seen in our patient FS, yet has detectable transcript in an EBV cell line.

Two of the patients reported here have WAS yet produce normal amounts of WASP in EBV-transformed cell lines, and in the spleen in the case of patient IA. The patient MD was shown by cDNA sequence analysis to have an exon 1 mutation causing a single nonconservative amino acid substitution. No other mutations of the WASP coding sequence were found. Since the mutant protein is present in normal amounts, this supports the hypothesis that the $\mathrm{NH}_{2}$-terminal portion of WASP is critical for platelet function and/or survival, but perhaps less so for immune system integrity (5-7). The patient IA was shown to have an insertion-deletion pair in exon 10 resulting in 4 amino acid substitutions in a proline-rich portion of WASP (amino acids 312-460) that may be involved in SH3 domain binding. No single amino acid substitution mutations in this region of WASP have yet been identified, only nonsense mutations (5-8). As suggested by Derry et al. (7), it may be that this region of WASP has redundancy in structure due to the high number of proline residues, making it somewhat resistant to loss of function by single amino acid substitution mutations. The mutations seen in our patient IA, which cause four substitutions, would be consistent with this hypothesis. This patient has normal amounts of WASP in the EBV cell line and in the spleen, indicating that the change of four amino acids did not alter protein stability. Since his phenotype was characterized by severe, symptomatic thrombocytopenia, with little eczema and no immune defect, it is likely that this mutation (as in patient MD) affects platelet function and survival more than immune system function.

In summary, we have produced monoclonal antibodies to the Wiskott-Aldrich protein, and using these antibodies we have shown that WASP is produced in normal platelets, lymphocytes and monocytes. We have shown for the first time that a subset of WAS patients produce normal amounts of full size protein. In the two patients we studied that produce protein, both were shown to have amino acid substitution mutations by cDNA sequence analysis, thus identifying regions of WASP essential for its function. The monoclonal antibodies described here may have further uses in cell staining and in vitro studies.

Note added in proof. Two recent reports have shown that WASP binds to CDC42Hs and Rac, small GTPases involved in regulation of cytoskeletal formation:

Aspenström, P., U. Lindberg, and A. Hall. 1996. Two GTPases, $\mathrm{Cdc} 42$ and Rac, bind directly to a protein implicated in the immunodeficiency disorder Wiskott-Aldrich syndrome. Curr. Biol. 6:70-75.

Symons, M., J.M.J. Derry, B. Karlak, S. Jiang, V. Lemahieu, F. McCormick, U. Francke, and A. Abo. 1996. 
Wiskott-Aldrich syndrome protein, a novel effector for the GTPase CDC42Hs, is implicated in actin polymerization. Cell. 84:723-734.

\section{Acknowledgments}

The authors gratefully acknowledge the assistance of Dr. Harvey R. Gralnick and Kristin Hansmann in the preparation of platelets, Mrs. W. Pellegrini in the immunostaining experiments, Linda Greif and Mohamed Tantawi for their help in cDNA sequencing, and Faith May in providing elutriated monocytes.

\section{References}

1. Aldrich, R.A., A.G. Steinberg, and D.C. Campbell. 1954. Pedigree demonstrating a sex-linked recessive condition characterized by draining ears, eczematoid dermatitis and bloody diarrhea. Pediatrics. 13:133-138.

2. Rosen, F.S., M.D. Cooper, and M.D. Wedgwood. 1995. The primary immunodeficiencies. N. Engl. J. Med. 333:431-440.

3. Derry, J.M.J., H.D. Ochs, and U. Francke. 1994. Isolation of a novel gene mutated in Wiskott-Aldrich syndrome. Cell. 78:635-644.

4. Derry, J.M.J., H.D. Ochs, and U. Francke. 1994. Isolation of a novel gene mutated in Wiskott-Aldrich syndrome. Cell. 79:923. Published Erratum.

5. Kwan, S., T.L. Hagemann, B.E. Radtke, R.M. Blaese, and F.S. Rosen. 1995. Identification of mutations in the Wiskott-Aldrich syndrome gene and characterization of a polymorphic dinucleotide repeat at $D X S 6940$, adjacent to the disease gene. Proc. Natl. Acad. Sci. USA. 92:4706-4710.

6. Kolluri, R., A. Shehabedin, M. Peacocke, A. Lamhonwah, K. TeichertKuliszewska, S.M. Weissman, and K. Siminovitch. 1995. Identification of WASP mutations in patients with Wiskott-Aldrich syndrome and isolated thrombocytopenia reveals allelic heterogeneity at the WAS locus. Hum. Mol. Genet. 4:1119-1126.

7. Derry, J., J. Kerns, K. Weinberg, H. Ochs, V. Volpini, X. Estivill, A.P. Walker, and U. Franke. 1995. WASP gene mutations in the Wiskott-Aldrich syndrome and X-linked thrombocytopenia. Hum. Mol. Genet. 4:1127-1135.

8. Villa, A., L. Notarangelo, P. Macchi, E. Mantuano, G. Cavagni, D. Brugnoni, D. Strina, M. Patrosso, U. Ramengni, M. Sacco, A. Ugazio, and P. Vezzoni. 1995. X-linked thrombocytopenia and Wiskott-Aldrich syndrome are alleleic diseases with mutations in the WASP gene. Nat. Genet. 9:414-417.

9. Wengler, G.S., L.D. Notarangelo, S. Berardelli, G. Pollonni, P. Mella, A. Fasth, A.G. Ugazio, and O. Parolini. 1995. High prevalence of nonsense, frame shift, and splice-site mutations in 16 patients with full-blown Wiskott-Aldrich syndrome. Blood. 86:3648-3654.

10. Nelson, D.L., B.M. Bundy, H.E. Pitchon, R.M. Blaese, and W. Strober. 1976. The effector cells in human peripheral blood mediating mitogen-induced cellular cytotoxicity and antibody-dependent cellular cytotoxicity. J. Immunol. 117:1472-1481

11. Frorath, B., C.C. Abney, H. Berthold, M. Scanarine, and W. Northemann. 1992. Production of recombinant rat interleukin-6 in Escherichia coli using a novel highly efficient expression vector pGEX-3T. Biotechniques. 12:558-563.

12. Bradford, M.M. A rapid and sensitive method for the quantitation of microgram quantities of protein utilizing the principle of protein dye binding. Anal. Biochem. 72:248-254.

13. Fuller, S.A., M.J. Takhashi, and J.G.R. Hurrell. 1988. Fusion of myeloma cells with immune spleen cells. In Current Protocols in Molecular Biology. F.M. Ausubel, R. Brent, R.E. Kingston, D.D. Moore, J.A. Smith, J.G. Seiddman, and K. Struhl, editors. Green Publishing Associates and WileyInterscience, New York. 11-7-1-11-7-4.

14. Stewart, D.M., C.C. Kurman, and D.L. Nelson. 1995. Production of monoclonal antibodies to Bruton's tyrosine kinase. Hybridoma. 14:243-246.

15. Corash L, H. Tan, and H.R. Gralnick. 1977. Heterogeneity of human whole blood platelet subpopulations. I. Relationship between buoyant density, cell volume and ultrastructure. Blood. 49:71-87.

16. Bock, G.H., C.M. Long, M.L. Riley, J.D. White, C.C. Kurman, T.A. Fleisher, M. Tsokos, M. Brown, D. Serbousek, W.D. Schwieterman, and D.L. Nelson. 1993. Characterization of a new IL-6 dependent human B-lymphoma cell line in long term culture. Cytokine. 5:480-489.

17. Yarchoan, R., G. Tosato, R.M. Blaese, R.M. Simon, and D.L. Nelson. 1983. Limiting dilution analysis of Epstein-Barr virus-induced immunoglobulin production by human B cells. J. Exp. Med. 157:1-14.

18. Gallagher, S., S.E. Winston, S.A. Fuller, and J.G.R. Hurrell. 1993. Immunoblotting and immunodetection. In Current Protocols in Molecular Biology. F.M. Ausubel, R. Brent, R.E. Kingston, D.D. Moore, J.A. Smith, J.G. Seidman, and K. Struhl, editors. Green Publishing and Wiley Interscience, New
York. 10-8-1.

19. Selden, R.F. 1989. Analysis of RNA by Northern hybridization. In Current Protocols in Molecular Biology. F.M. Ausubel, R. Brent, R.E. Kingston, D.D. Moore, J.A. Smith, J.G. Seidman, and K. Struhl, editors. Green Publishing and Wiley Interscience, New York. 4-9-1.

20. Bergstrom, C.P., C.R. Wagner, D.K. Ann, and P.E. Hanna. 1995. Hamster monomorphic arylamine $N$-acetyltransferase: expression in Escherichia coli and purification. Protein Expr. Purif. 6:45-55.

21. Rabinovsky, E.D., D.P. Browder, and J.L. McManaman. 1994. Preparation and affinity purification of a novel, biologically active, CNTF fusion protein. Biochem. J. 305:753-759.

22. Baldini, M.G. 1972. Nature of the platelet defect in the Wiskott-Aldrich syndrome. Ann. NY Acad. Sci. 201:437-444.

23. Murphy, S., F.A. Oski, J.L. Naiman, C.J. Lusch, S. Goldberg, and F.H Gardener. 1972. Platelet size and kinetics in hereditary and acquired thrombocytopenia. N. Engl. J. Med. 286:499-504.

24. Ochs, H.D., S.J. Slichter, L.A. Harker, W.E. Von Behrens, R.A. Clark, and R.J. Wedgewood. 1980. The Wiskott-Aldrich syndrome: studies of lymphocytes, granulocytes and platelets. Blood. 55:243-252.

25. Cooper, M.S., H.P. Chase, J.T. Lowman, W. Krivit, and R.A. Good 1968. Wiskott-Aldrich syndrome: an immunologic deficiency disease involving the afferent limb of immunity. Am. J. Med. 44:499-513.

26. Blaese, R.M., W. Strober, R.S. Brown, and T.A. Waldmann. 1968. The Wiskott-Aldrich syndrome: a disorder with a possible defect in antigen processing or recognition. Lancet. i:1056-1061.

27. Oppenheim, J.J., R.M. Blaese, and T.A. Waldmann. 1970. Defective lymphocyte transformation and delayed hypersensitivity in Wiskott-Aldrich syndrome. J. Immunol. 104:835-844.

28. Molina, I.L., D.M. Kenney, F.S. Rosen, and E. Remold-O'Donnell 1992. T cell lines characterize events in the pathogenesis of the Wiskott-Aldrich syndrome. J. Exp. Med. 176:867-874.

29. Molina, I.J., J. Sancho, C. Terhorst, F. S. Rosen, and I. Remold-O'Donnell. 1993. T cells of patients with the Wiskott-Aldrich syndrome have a restricted defect in proliferative responses. J. Immunol. 151:4383-4390.

30. Parkman, R., E. Remold-O'Donnell, D.M. Kenney, S. Perrine, and F.S Rosen. 1981. Surface protein abnormalities in lymphocytes and platelets from patients with Wiskott-Aldrich syndrome. Lancet. ii:1387-1389.

31. Remold-O'Donnell, E., and F.S. Rosen. 1990. Sialophorin (CD43) and the Wiskott-Aldrich syndrome. 1990. Immunodef. Rev. 2:151-174.

32. Piller, F., F. Le Deist, K.I. Weinberg, R. Parkman, and M. Fukuda. 1991. Altered $O$-glycan synthesis in lymphocytes from patients with Wiskott-Aldrich syndrome. J. Exp. Med. 173:1501-1510.

33. Higgins, E.A., K.A. Siminovitch, D. Zhuang, I. Brockhausen, and J.W. Dennis. 1991. Aberrant $O$-linked oligosaccharide biosynthesis in lymphocytes and platelets from patients with the Wiskott-Aldrich syndrome. J. Biol. Chem. 266:6280-6290.

34. Greer, W.L., E. Higgins, D.R. Sutherland, A. Novogrodsky, I. Brockhausen, M. Peacocke, L.A. Rubin, M. Baker, J.W. Dennis, and K.A. Siminovitch. 1989. Altered expression of leucocyte sialoglycoprotein in Wiskott-Aldrich syndrome is associated with a specific defect in $\mathrm{O}$-glycosylation. Biochem. Cell Biol. 67:503-509.

35. Simon, H., G.B. Mills, S. Hashimoto, and K.A. Siminovitch. 1992. Evidence for defective transmembrane signaling in B cells from patients with Wiskott-Aldrich syndrome. J. Clin. Invest. 90:1396-1405.

36. Poplack, D.G., G.D. Bonnard, B.J. Holiman, and R.M. Blaese. 1976. Monocyte-mediated antibody-dependent cellular cytotoxicity: a clinical test of monocyte function. Blood. 48:809-816.

37. Rivero-Lezcano, O.M., A. Marcilla, J.H. Smeshima, and K.C. Robbins. 1995. Wiskott-Aldrich syndrome protein physically associates with Nck through Src homology 3 domains. Mol. Cell. Biol. 15:5725-5731.

38. Aldovini, A., C. Debouck, M.B. Feinberg, M. Rosenberg, S.K. Arya, and F. Wong-Staal. 1986. Synthesis of the complete trans-activation gene product of human T-lymphocyte virus type III in Escherichia coli: demonstration of immunogenicity in vivo and expression in vitro. Proc. Natl. Acad. Sci. USA. 83: 6672-6676.

39. Ferguson, B., N. Jones, J. Richter, and M. Rosenberg. 1984. Adenovirus E1a gene product expressed at high levels in Escherichia coli is functional. Science (Wash. DC). 224:1343-1346.

40. Van Beveren, C., F van Straaten, T. Curran, R. Müller, and I.M. Verma. 1983. Analysis of FBJ-MuSV provirus and $c$-fos (mouse) gene reveals that viral and cellular fos gene products have different carboxy termini. Cell. 32 1241-1255.

41. Watt, R.A., A.P. Shatzman, and M. Rosenberg. 1985. Expression and characterization of the human c-myc DNA-binding protein. Mol. Cell. Biol. 5: 448-456.

42. Simpson, S.B, and C.M. Stoltsfus. 1994. Frameshift mutations in the $v$-src gene of avian sarcoma virus act in cis to specifically reduce $v$-src mRNA levels. Mol. Cell. Biol. 14:1835-1844. 